\title{
An Investigation into the Evolution Law of Young's Modulus of Polyurethane Coatings with Diluent Contents by Microstructure- Based Tests
}

\author{
Chao Xie, Xiaoxu Lin, Qicai Wang $\mathbb{D}$, Bentian Yu, and Sheng Li $\mathbb{D}$ \\ Lanzhou Jiaotong University, Lanzhou, Gansu730070, China \\ Correspondence should be addressed to Qicai Wang; xieyue111000@163.com
}

Received 22 October 2021; Revised 27 December 2021; Accepted 3 January 2022; Published 18 February 2022

Academic Editor: Veronica Calado

Copyright (c) 2022 Chao Xie et al. This is an open access article distributed under the Creative Commons Attribution License, which permits unrestricted use, distribution, and reproduction in any medium, provided the original work is properly cited.

\begin{abstract}
Recent studies have indicated that the addition of a diluent significantly affect its mechanical properties and performance of a coating, but no works have been reported on the influence of diluent content on the Young's modulus of a coating, and the evolution law between them is also not clear. To address the deficiency, polyurethane coatings (paint samples) with different diluent contents were prepared. Force-displacement curves and microscan images of the coatings were obtained by atomic force microscopy, and the Young's modulus of the coatings was calculated on the basis of the indentation method, and positron annihilation lifetime spectroscopy was used to test the microstructure of the coatings. The results reveal that: (i) Young's modulus of the coating initially increase and then decreases with diluent content increasing; (ii) the free-volume aperture size had a greater effect on Young's modulus by grey correlation analysis.
\end{abstract}

\section{Introduction}

The addition of coating as a protective layer can effectively improve the surface properties of a substrate, such as through abrasion resistance and corrosion resistance $[1,2]$. In the coatings industry, polyurethane is widely used in various surface protection applications because of its excellent weather resistance, chemical resistance, water resistance, and flexibility at low temperatures, among other advantages $[3,4]$. Studies have shown that the mechanical properties of the cured coating can seriously affect its using effect [5]. Among the many mechanical performance indexes of a coating, the Young's modulus is one of the most critical and represents the relationship between elastic deformation and applied stress [6]. The mechanical response, cracking, spalling, and residual stress state of the coating during the process of application are all related to the Young's modulus of the material [7-9]. Therefore, study into the Young's modulus of a coating is crucial to the prediction of its performance upon application [10].
Saalah et al. [11] studied the effect of the extent of $\mathrm{OH}$ in polyols on the mechanical properties of polyurethane coating, and the results showed that the Young's modulus increased with an increase in the number of hydroxyl groups. This was attributed to the higher concentration of $\mathrm{OH}$ groups providing more cross-linking sites for the formation of hydrogen bonds on hard segment chains. Similarly, Hwang et al. [12] found that increasing the crosslinking density of polyurethane reduced the fluidity of the chain segment, thus providing improved resistance to external tensile force, increasing the elastic modulus of the coating, and reducing the deformation when subjected to an external load. Zheng et al. [13] reported that phase separation significantly affects the mechanical properties of polyurethane, and that the absence of phase separation leads to a decrease in Young's modulus and strain at the fracture site. Brunette et al. [14] and Li et al. [15] found that the Young's modulus and other mechanical properties of polyurethane coatings were closely related to the content ratio of the hard and soft segments, and that the elastic modulus decreased with an increasing content of soft 
segments. Finnigan et al. [16] demonstrated that adding layered silicate nanometer powder into the polyurethane system would not destroy the phase separation, but the increase in the elastic modulus was obvious. Han et al. [17] found that the Young's modulus of most polyurethane-clay composite samples was lower than that of pure polyurethane. Valentine et al. [18] pointed out that the properties of polyurethane materials were usually tested only at a low strain rate of uniaxial tension under dry, room temperature conditions. However, studies found that the Young's modulus of polyurethane coating was significantly correlated with the temperature and humidity of the test environment.

The aforementioned studies explored the effects of various factors on the Young's modulus of polyurethane coating from different perspectives. The fluidity of the paint is commonly adjusted by adding diluent, with the extent of the adjustment determined per the engineering demands for the specific application [19]. Meanwhile, the addition of diluent also has an impact on the performance of a cured coating $[20,21]$. However, there no works reported on the influence of diluent content on the Young's modulus of coatings. Therefore, deepening the knowledge of this problem forms the main objective of the present study.

The study described herein designed paint systems with different diluent contents and prepared corresponding polyurethane coatings by a spin-coating method. The forcedisplacement curve between the probe and the coating was measured by atomic force microscopy (AFM) [22]. Furthermore, a method for calculating Young's modulus of each coating was developed and applied to each coating on the basis of an AFM pyramidal probe test, which considers the force-indentation relationship of the pyramidal punch [23], and previous results obtained from an indentation technique $[24,25]$. In addition, positron annihilation technology $[26,27]$ was used to investigate the free volume of each coating group, with subsequent analysis performed for the variation law of Young's modulus from the microscopic perspective. Finally, the relationship between the free volume indexes and the Young's modulus of each coating was quantitatively determined using grey relation theory.

\section{Material and Methods}

2.1. Materials. The polyurethane paint and diluent used were provided by Urumqi You Bao Te Anti-corrosion Paint Co. Ltd. The polyurethane paint (BS52-40 type) was a one-component moisture-curing paint, and the diluent was nonactive diluent matched with polyurethane anticorrosive paint.

2.2. Sample Preparation. The original intention of this study is to provide some theoretical basis for the construction of the actual project, so the use of coating in the actual project is also referred to in the design test. Relevant study [19] indicates that in practical engineering, the fluidity of coating is usually adjusted by diluent to ensure the smooth completion of construction, and pure polyurethane coating without diluent will not be used in the actual project. Considering the application of coating in practical engineering and the current research situation, the addition amount of diluent is designed in five cases from higher level to lower one to prepare the experimental paint, then the influence of diluent content on Young's modulus of coatings will be. In this paper, the diluents were added as $10 \%, 15 \%, 20 \%, 25 \%$, and $30 \%$ of the mass of polyurethane coating, and these samples are hereafter denoted as C-10, C-15, C-20, C-25, and C-30, respectively. A glass slide $(1.5 \mathrm{~cm}$ in length) was used as the substrate and fixed in the center of the homogenizer (KW4A type desktop homogenizer; Shanghai Camet Company). The prepared coating was dropped $(1 \mathrm{~mL})$ onto the substrate, which was placed in the instrument, and the coating was spread evenly over the substrate under the effect of the centrifugal force. The spinning rate was 2500 revolutions per minute and the rotation time was 40 seconds. Finally, the cured coating sample was put in a sealed bag for testing to prevent contamination of the surface.

2.3. AFM. Microscopic images of the coating and forcedisplacement curves between the probe and the sample were measured by AFM (MFP-3D type, Asylum Research Instrument Co. Ltd.). Images were collected using the tapping mode and the force-displacement curve was measured by the contact mode. The probe used in this study is a FM-type probe produced by Nano World, with a spring constant and resonance frequency of $2.8 \mathrm{~N} / \mathrm{m}$ and $75 \mathrm{kHz}$, respectively. The exact spring constant was determined by the thermal tune method before each measurement. The parameters after debugging the instrument were: spring constant $=2.5 \mathrm{nN} /$ $\mathrm{nm}$; scan rate $=1 \mathrm{~Hz}$; set point $=0.2 \mathrm{~V}$. Each image had a scanning area of $2 \mu \mathrm{m} \times 2 \mu \mathrm{m}$. All experiments were conducted in an environment with a relative humidity of about $38 \%$ and a temperature of $22 \pm 2^{\circ} \mathrm{C}$.

2.4. PALS. The microstructural information of the coating was tested using PALS, with the experiments carried out on the positron research platform of the Institute of High Energy Physics, Chinese Academy of Sciences. The positron annihilation lifetime spectrum was measured by fast-slow coincidence measurement technology and the time resolution of the spectrometer was about $195 \mathrm{ps}$. The lifetime spectrum was measured with two million counts to ensure statistical accuracy and the LT9.0 program was used to analyze the positron lifetime spectra [27].

2.5. Transmission Electron Microscopy (TEM). The morphology of the AFM probe tip was imaged with a transmission electron microscope (JEM-2100F, JEOL Ltd., Japan) operated at $200 \mathrm{kV}$ and a magnification of 100,000. Images are shown in Figure 1.

\section{Results and Discussion}

3.1. AFM Data Processing and Calculation of Young's Modulus. Hertz theory is commonly used to analyze contact mechanics problems [28], and the indentation method 


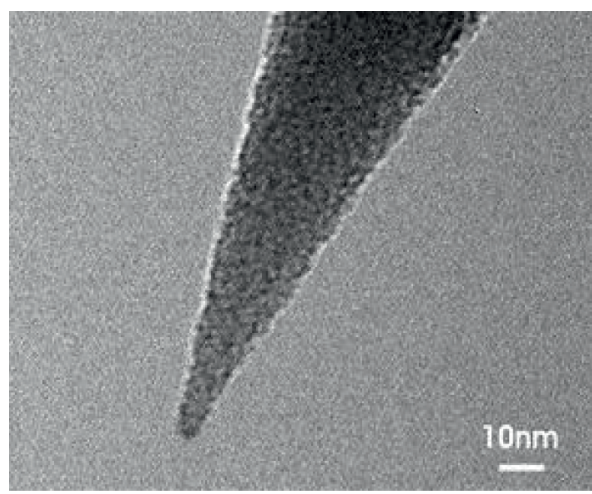

(a)

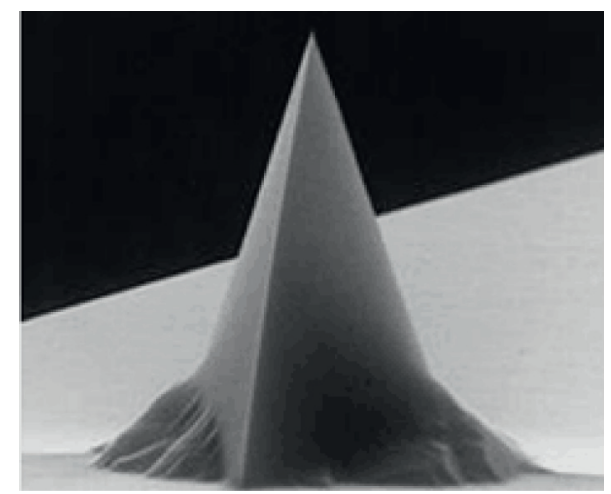

(b)

FIGURE 1: Morphology of AFM probe tip: (a) micrograph of TEM for probe tip; (b) the shape diagram provided by the production company.

established on the basis of Hertz theory has been widely applied to the determination of Young's modulus of coating films $[24,25]$. For probes with different geometric tips, their test results will be different, and the contact model applicable to the indentation method will also be different [29]. In AFM technology, spherical or conical tip probes [30-32] are most often used, and they are suitable for smooth surface and hard texture samples. However, when the indentation depth during AFM testing is larger than the apparent radius of curvature of the probe tip (10 nm-50 nm), the accuracy of the above calculation method will be seriously reduced [29]. For samples with soft texture and a wide range of indentation depth testing, such as the polyurethane coating tested in this paper, it is appropriate to use a pyramid-tipped probe, which can achieve more accurate testing results [33]. Therefore, this paper will use pyramid tip probe for experimental research. The tip shape is positive triangular pyramid shape, as shown in Figure 1. In this case, the corresponding mechanical contact model will also change, and there are few reports on this case. Therefore, this paper will combine AFM test results to explore a new calculation method to determine the young's modulus of the coatings.

Previous literature [23] has proposed a force-indentation calculation relationship for the case of a pyramid-shaped punch:

$$
F=\frac{C_{0} G \delta^{2}}{(1-\mu) \tan \alpha}
$$

where $\mathrm{F}$ is the load applied to the coating (in units of $\mathrm{nN}$ ); $\delta$ is the depth of the indentation generated under different loads (in $\mathrm{nN}$ ); and $G$ and $\mu$ are the shear modulus and Poisson's ratio of the coating, respectively. $\alpha$ is the angle between the side and the bottom of the probe tip. In this study, the probe tip is a triangular pyramid, where $\tan \alpha=2 \sqrt{2}$. $\mathrm{C}_{0}$ is the influence coefficient of the relationship between the force and indentation depth caused by the change in the tip geometry. Accounting for the number of pyramids (n), these influence coefficients are listed in Table 1.

The shear modulus (G), Young's modulus (E), and Poisson's ratio $(\mu)$ are all related according to equation (2) [29], yields equation (3). This then describes the relationship among the $E$ of a coating, the applied load, and the indentation depth. Finally, by applying the known parameters for the positive triangular pyramidal probe used in this study, the relationship between load and indentation depth is given by equation (4).

$$
\begin{aligned}
& G=\frac{E}{2(1+\mu)}, \\
& F=\frac{C_{0} E}{2\left(1-\mu^{2}\right) \tan \alpha} \delta^{2}, \\
& F=0.3141 \times\left(\frac{E \delta^{2}}{1-\mu^{2}}\right) .
\end{aligned}
$$

Figure 2 shows a typical force-displacement curve, in which $\mathrm{A}-\mathrm{B}-\mathrm{C}$ is the approach curve and $\mathrm{C}-\mathrm{D}-\mathrm{A}$ is the withdrawal curve. More specifically, section A-B in the figure shows the process when the probe gradually approaches the sample surface. At this stage, the probe cantilever gradually bends downward from the initial state of no load and the distance between the tip and the sample decreases continuously. When the distance between the tip and the sample reaches a certain small value, the surface forces (van der Waals force and electrostatic force) are large enough for the probe to jump and make contact with the surface of the sample (Point B in the figure). As the cantilever of the probe continues to move down, the tip presses into the surface of the sample until the force peaks at Point C. The B-C section of the curve provides relevant information about the mechanical properties of the sample [34]. When the force on the cantilever reaches a predetermined value, the probe begins the withdrawal section of the test cycle. Before Point $\mathrm{D}$, the probe maintains contact with the sample surface due to adhesion forces. However, at Point D, the adhesive force peaks and the cantilever deflects in the reverse direction (relative to Point B). The probe then separates from the sample and the cantilever returns to the initial position (Point A).

To calculate the $E$ of the coating, it is necessary to derive the force-indentation depth relationship from the forcedisplacement curve. The force exerted on the coating surface 
TABLE 1: Force-indentation coefficients.

\begin{tabular}{lccccccccc}
\hline Number of pyramids & 3 & 4 & 5 & 6 & 8 & 10 & 15 & 20 & 50 \\
\hline Influence coefficient $\left(\mathrm{C}_{0}\right)$ & 1.777 & 1.491 & 1.398 & 1.355 & 1.316 & 1.300 & 1.285 & 1.280 & 1.274 \\
\hline
\end{tabular}

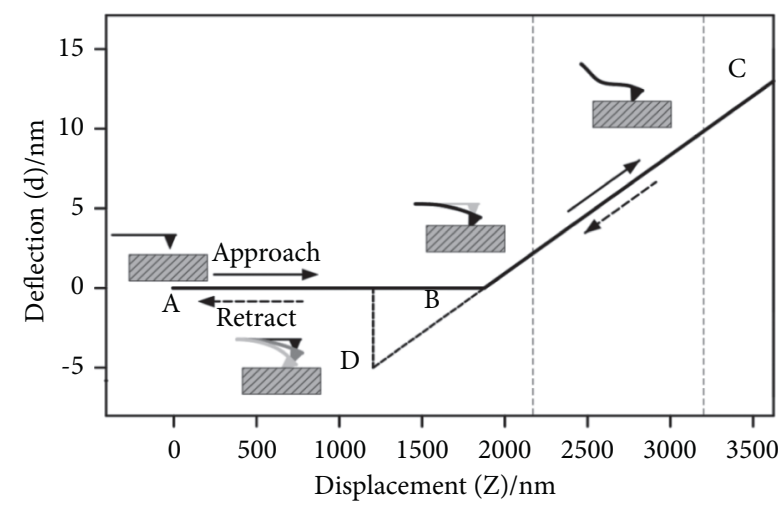

FIgURE 2: Force-displacement curve.

by the cantilever can be calculated from Hooke's Law (equation (5)) with the spring constant of the cantilever:

$$
\begin{aligned}
& F=k_{c} d, \\
& \delta=Z-d .
\end{aligned}
$$

The indentation depth is calculated using equation (6), where $Z$ is the piezo displacement, and $d$ is the deflection of the cantilever, as shown in Figure 3.

Because of thermal drift in the detection system and the stress of the cantilever beam, the deflection of the free cantilever was not equal to zero. Therefore, the deflection offset, $d_{0}$ [35], should be subtracted from all deflection values. This offset was determined from the force-displacement curve by measuring the average cantilever deflection when the cantilever was far from the sample surface. Therefore, equation (5) can be written as:

$$
F=k_{c}\left(d-d_{0}\right)
$$

Similarly, considering that the tip of the probe has a height deviation of $Z_{0}$ when it initially contacts the surface of the sample, equation (6) becomes equation (8):

$$
\delta=\left(Z-Z_{0}\right)-\left(d-d_{0}\right) .
$$

By combining equations (7) and (8) with the approach portion of the force-displacement curve measured by AFM (B-C section in Figure 2), the relationship diagram between the force and indentation depth can be obtained. The force-indentation depth relationships of each coating group are shown in Figure 4.

Poisson's ratio was taken as the reference value [36], the force-indentation depth curve was fitted and analyzed using the model deduced above, and the $E$ of each coating was obtained, as shown in Table 2:

The calculated $E$ of the coatings ranged over 6.12-6.92 $\mathrm{MPa}$, which are in the same range as previously reported Young's modulus for polyurethane coatings

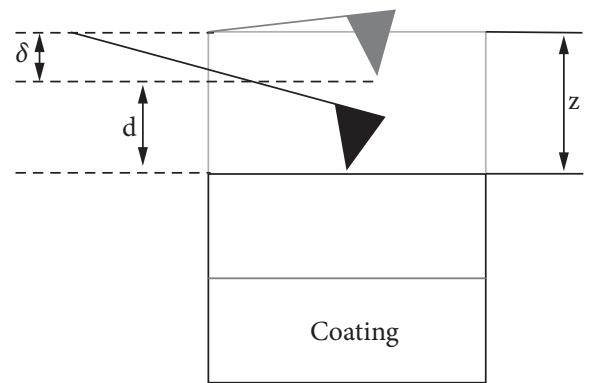

FIgURE 3: Relative movements of the sample-AFM tip system in the indentation experiment.

$[11,18,37]$. Compared with C-10, the $E$ of C-15, C-20, C-25, and C-30 increased by $3.9 \%, 13.1 \%, 8.5 \%$, and $6.4 \%$, respectively. This indicates that the diluent content in the paint has a significant effect on the $E$ of the coating.

It is clear from Table 2 that the $E$ of the cured coating initially increased and then decreased with increasing diluent content in the paint. This is because the diluent can reduce the curing rate of the coating and, hence, the curing reaction can be performed more completely. This increases the cross-linking density and improves the $E$ [12]. However, the addition of diluent also increases the free-volume concentration and size of the coating [38], as shown in Section 3.3. This will provide a larger space for the migration of molecular chain segments, and enables more flexible rotation of the side chains. This leads to easier movement of the molecular chain segments when the coating is subjected to an external load [39], which will reduce the E. Therefore, the $E$ exhibits an initial increase, followed by a decrease with increasing diluent content.

3.2. Microscan Images. To more intuitively research the change in $E$ of the coating, AFM was adopted to conduct microscopic image scanning. The phase diagram of each specimen is shown in Figure 5. During AFM scanning, smaller phase angles indicate harder or more rigid materials, whereas higher phase angles indicate the presence of softer material. Therefore, the lighter colored regions in the figure have lower hardness [40], which also indicates that their $E$ is smaller [41]. In contrast, the hardness of the darker colored regions is larger, which corresponds to a larger $E$.

As can be seen from the phase diagram, the highest phase angle of C-20 was only $52.5^{\circ}$ and the area of the high-phaseangle region was less than that of the other samples. This indicates that, overall, C-20 has a large E. However, the maximum phase angle observed in C-10 was $72.3^{\circ}$ and the high-phase-angle region was large; thus, its overall $E$ was small. The maximum phase angle and the corresponding area in samples C-15, C-25, and C-30 are somewhere in between $\mathrm{C}-10$ and C-20. 


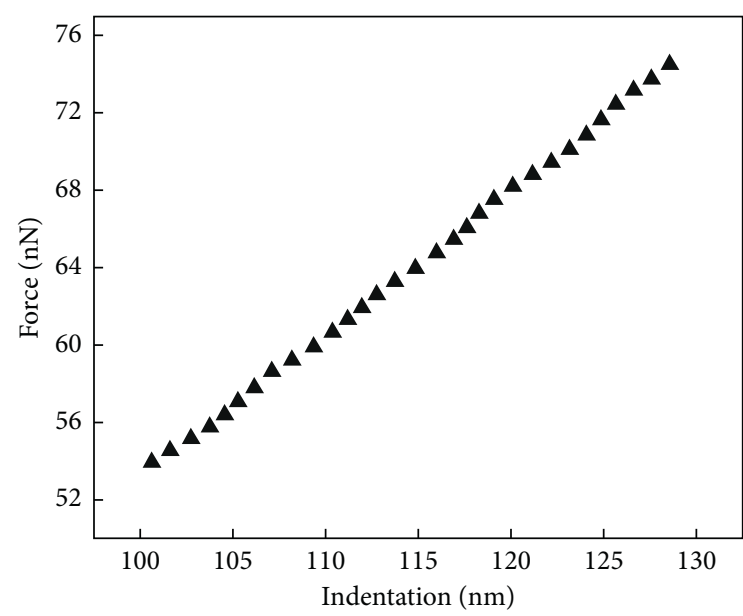

- $\mathrm{C}-10$

(a)

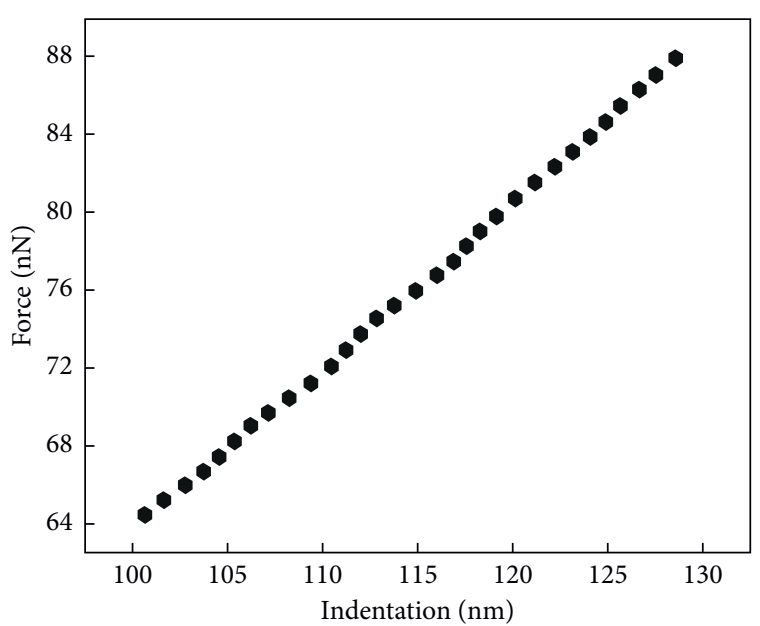

- C-20

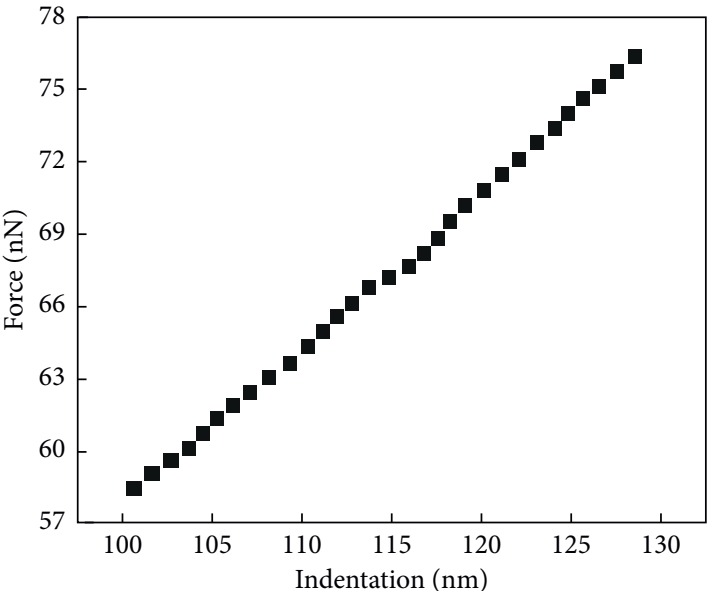

- $\mathrm{C}-15$

(b)

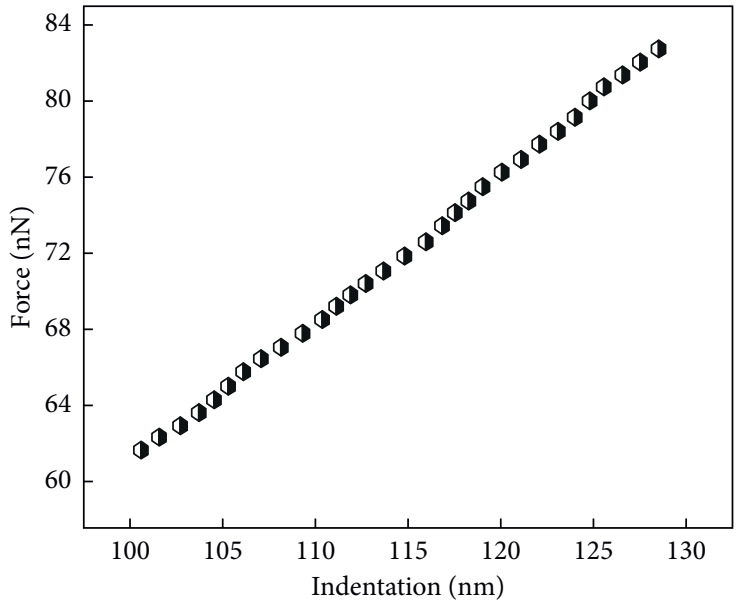

- C- 25

(c) (d)

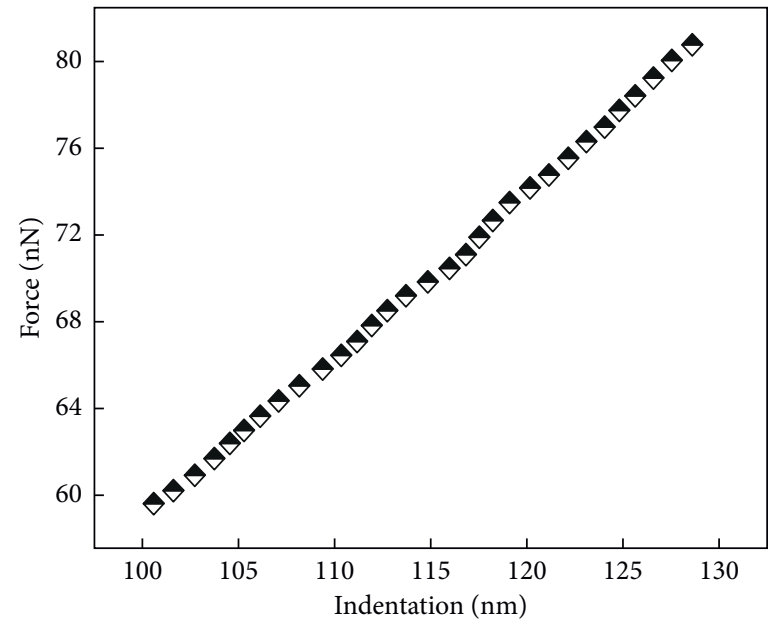

$\diamond \mathrm{C}-30$

(e)

Figure 4: Force-indentation depth chart of (a) C-10, (b) C-15, (c) C-20, (d) C-25, and (e) C-30. 
TABLE 2: Calculated Young's modulus data for coating samples.

\begin{tabular}{lcr}
\hline Sample & E (MPa) & $R^{2}$ \\
\hline C-10 & 6.12 & 0.9782 \\
C-15 & 6.36 & 0.9566 \\
C-20 & 6.92 & 0.9861 \\
C-25 & 6.64 & 0.9642 \\
C-30 & 6.51 & 0.9479 \\
\hline
\end{tabular}

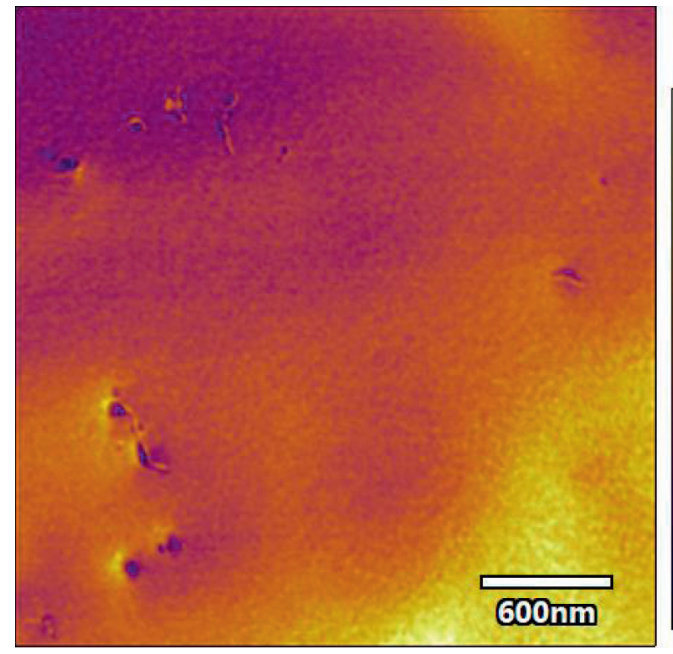

(a)

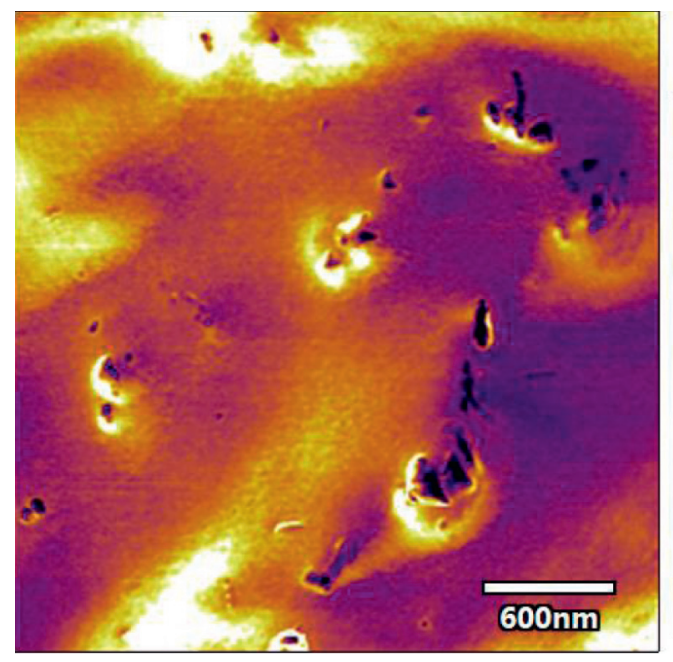

(c)

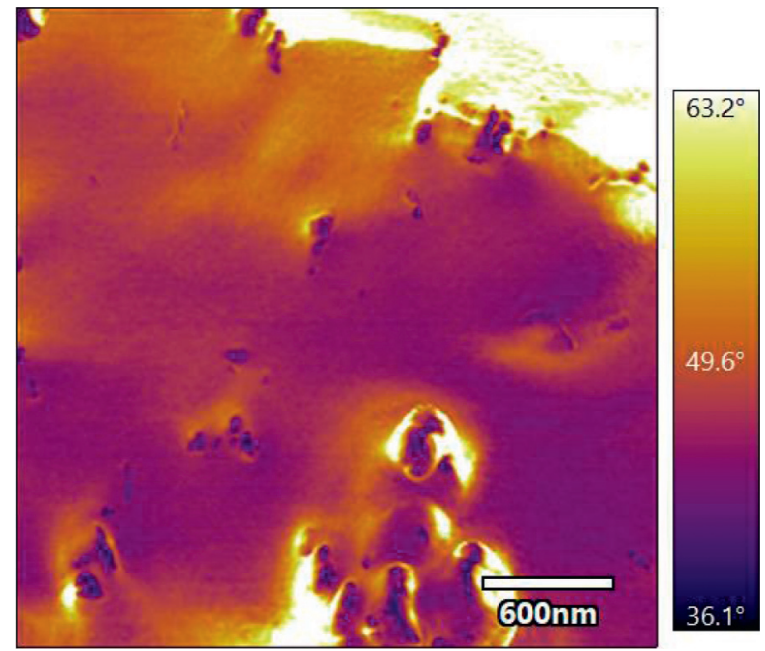

(b)

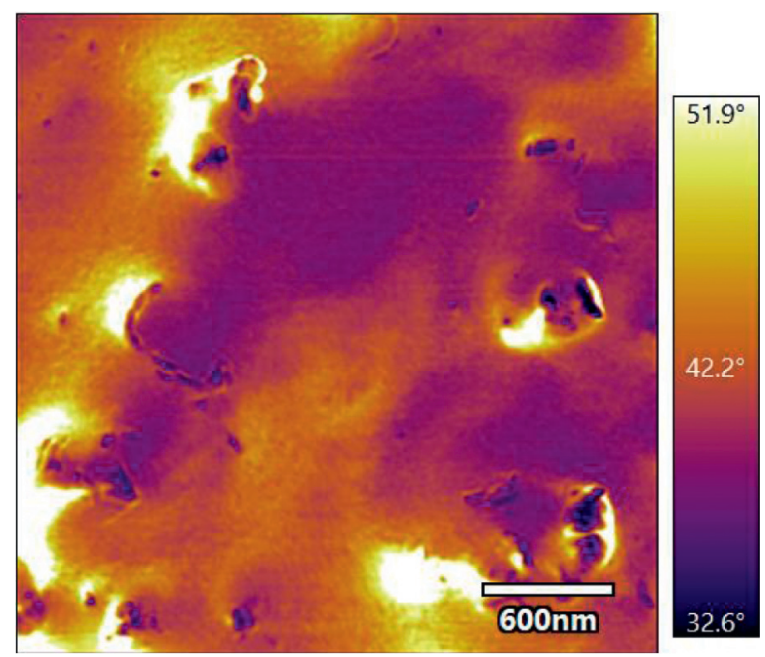

(d)

FIgURE 5: Continued. 


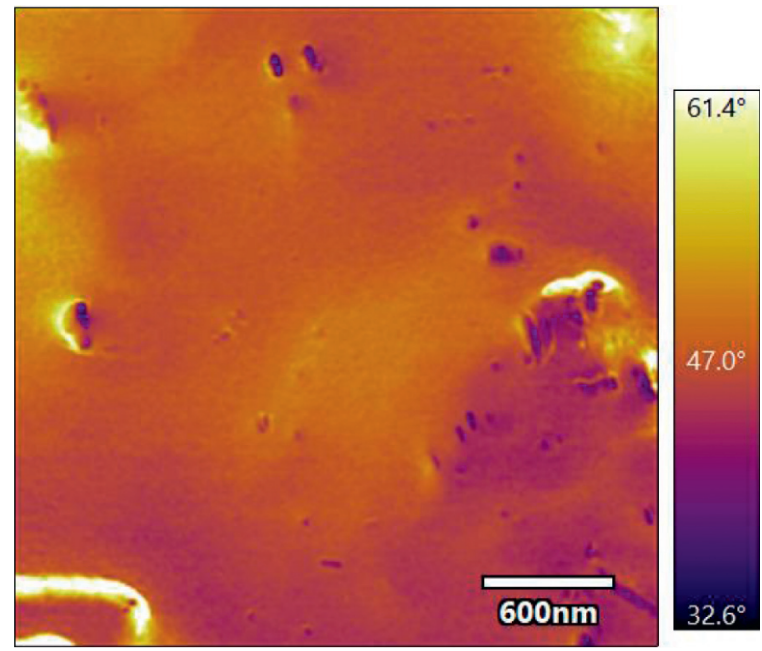

(e)

Figure 5: Phase diagram of (a) C-10, (b) C-15, (c) C-20, (d) C-25, and (e) C-30.

The same probe loading force was maintained during the scanning process for capturing each sample's indentation depth image. Therefore, the greater the pressing depth, the softer the coating texture, and the smaller the $E$ [41]. Therefore, in the indentation depth images, the $E$ of the coating in the lighter colored areas is smaller (deeper indentation). Conversely, the $E$ of the coating in the darker colored areas is larger. The indentation depth scanning results of each specimen are shown in Figure 6.

Under the same loading force, the maximum pressure depth of C-20 was only $1.38 \mathrm{~nm}$, while that of C-10 reached $2.38 \mathrm{~nm}$ in the scanning area. As the diluent content increased, the maximum pressure depth of the coating decreased firstly and then increased, and the area corresponding to the lighter color (i.e., deeper indentation depth indicating softer material) also showed the same trend. These results suggest that the overall $E$ of the coating initially increased and then decreased with increasing diluent content, as reflected in the phase diagrams and the calculation results in Section 3.1.

3.3. Free Volume. Free volume refers to the volume not occupied by molecules in the polymer, which is dispersed in the entire material in the form of holes. The free volume represents an intrinsic defect in polymer materials, and it includes the holes that exist between molecular chains and the spaces needed for the chains to move. The size of the free volume will directly affect the stacking density of chemical bonds $[42,43]$, thus also impacting the mechanical properties of materials [38]. Therefore, the free volume of each coating was tested to further analyze the variation law of the E.

PALS is an important method for measuring the free volume of a polymer [44-46], which provides microstructure information of the tested samples [47]. The positron annihilation lifetime spectrum was resolved into three lifetime components: $\tau_{1}, \tau_{2}$, and $\tau_{3}$ [48]. Among them, $\tau_{3}$ originated from $o$-Ps pick-off annihilation in the free volume holes in the polymer amorphous region, which can be localized preferentially in the cavities. Therefore, the $o$-Ps annihilation lifetime $\left(\tau_{3}\right)$ and intensity $\left(\mathrm{I}_{3}\right)$ were used to characterize the sample free volume aperture size and concentration (quantity), respectively [49-51].

The positron annihilation results for each sample are shown in Figure 7. $\tau_{3}$ and $\mathrm{I}_{3}$ decrease initially and then increase as the diluent content in the paint increases. This indicates that the aperture size and concentration of the free volume of the coating both decrease first and then increase with an increase in diluent content. In addition, comparison with the calculated results of $E$ of the coatings (Table 2) reveals that the $E$ gradually decreases with the increase of $\tau_{3}$ and $\mathrm{I}_{3}$. This is consistent with the conclusions presented in the literature [47-52], whereby an increase in the free volume aperture size and concentration will lead to deterioration of the mechanical properties of materials.

Compared with C-10, the $\tau_{3}$ of C-15, C-20, C-25, and C-30 decreased by $1.8 \%, 10.1 \%, 4.2 \%$, and $3.0 \%$; the $\mathrm{I}_{3}$ decreased by $2.8 \%, 11.4 \%, 9.5 \%$, and $6.0 \%$; and the $E$ increased by $3.9 \%, 13.1 \%, 8.5 \%$, and $6.4 \%$, respectively. It is not difficult to see that the change in free volume will have a significant impact on the $E$ of the coating. To further quantify the influence of the aperture size and concentration of the free volume on the $E$, grey relation theory [53] was used for the correlation analysis. The mapping variables (parent sequences) representing the behavior characteristics of the system were represented by the $E$ of the coating and were denoted as $X_{0}$. The $\tau_{3}$ and $\mathrm{I}_{3}$ of the coating were taken as the effective factors (subsequences) affecting the main behavior of the system, which were denoted as $X_{1}$ and $X_{2}$, respectively. By calculating the grey correlation degree, the influence of free volume aperture size and concentration on the $E$ of the coatings could then be analyzed quantitatively. The parameters used in the calculation are listed in Table 3.

Putting the calculated correlation coefficients from the above table into equation (9): 


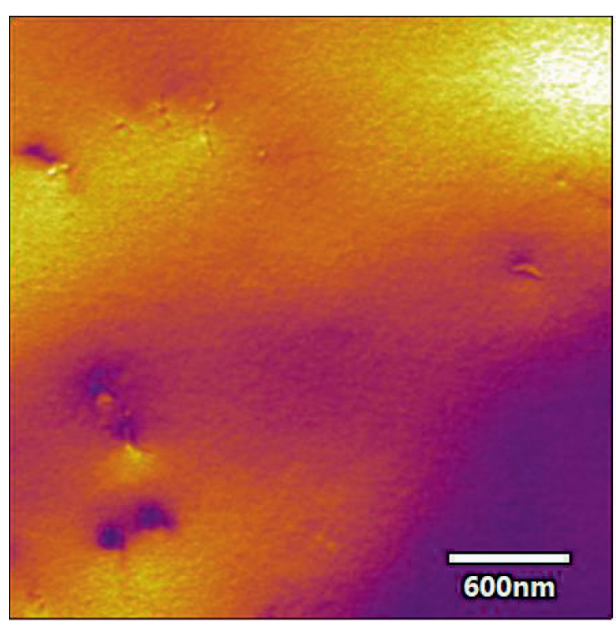

(a)

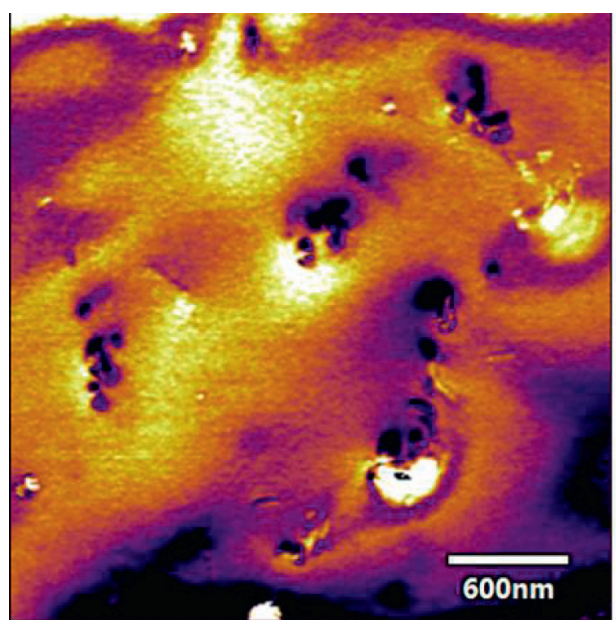

(c)

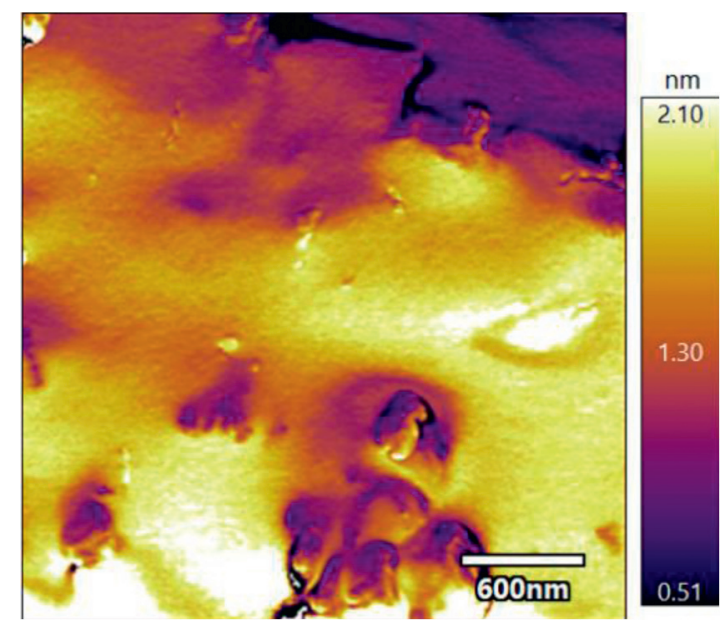

(b)

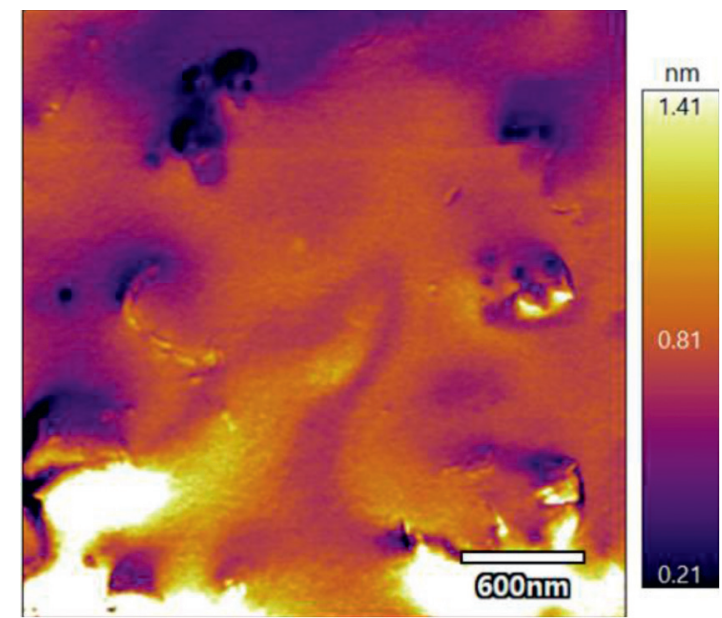

(d)

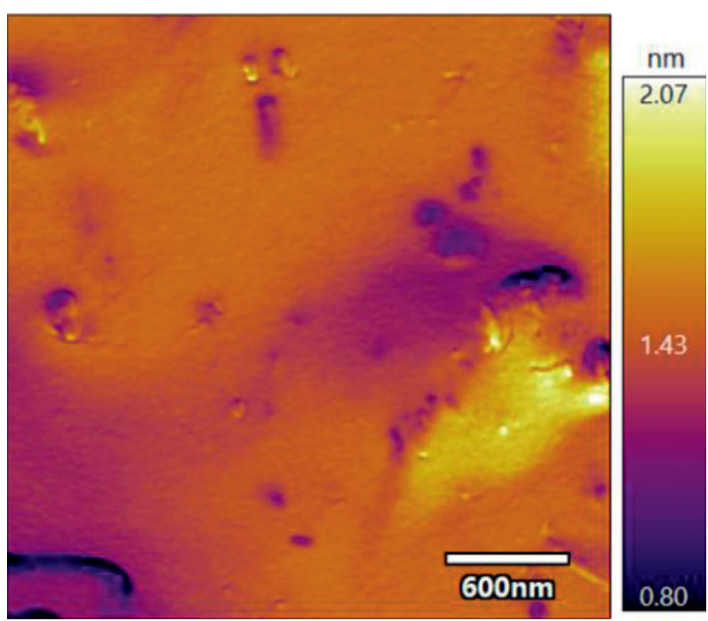

(e)

Figure 6: Indentation depth image of (a) C-10, (b) C-15, (c) C-20, (d) C-25, and (e) C-30. 


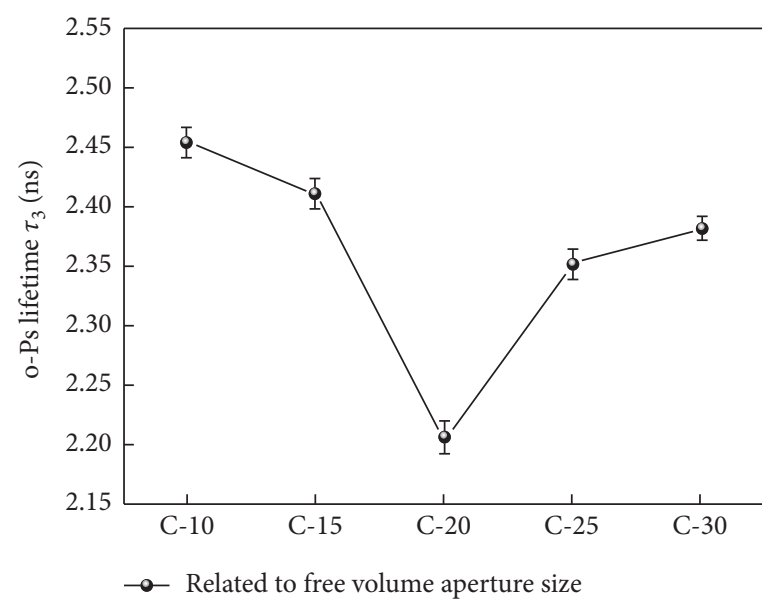

(a)

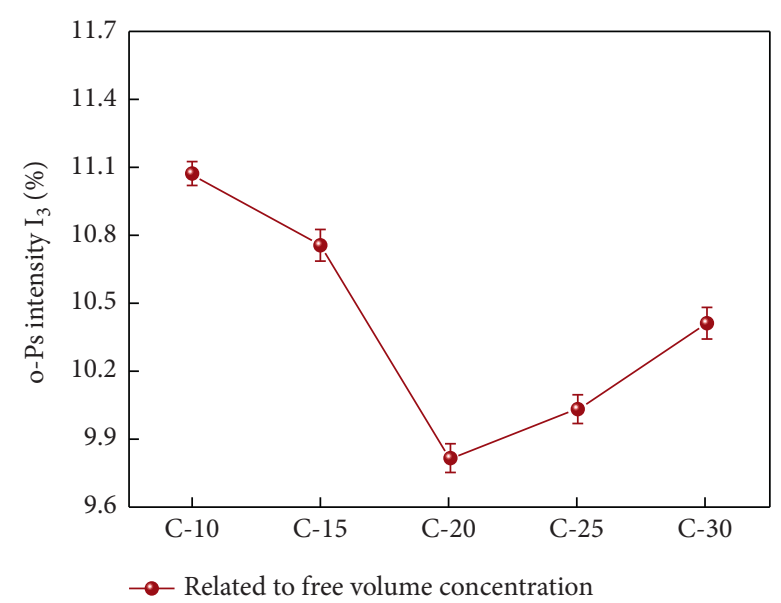

(b)

FIgUre 7: Positron annihilation test results: (a) $\tau_{3}$ of each sample and (b) $I_{3}$ of each sample.

TABLE 3: Calculated parameters for determining the grey correlation degree.

\begin{tabular}{|c|c|c|c|c|c|c|c|}
\hline \multirow[t]{2}{*}{ Sample } & \multicolumn{3}{|c|}{ Initial value image for each sequence } & \multicolumn{2}{|c|}{$\begin{array}{c}\text { Difference sequence } \\
\text { between each } \\
\text { subsequence and parent } \\
\text { sequence }\end{array}$} & \multicolumn{2}{|c|}{ Correlation coefficient } \\
\hline & $X_{0}^{\prime}$ & $X_{1}^{\prime}$ & $X_{2}^{\prime}$ & $\Delta_{1}$ & $\Delta_{2}$ & $\gamma_{01}(\mathrm{k})$ & $\gamma_{02}(\mathrm{k})$ \\
\hline $\mathrm{C}-10$ & 1 & 1 & 1 & 0 & 0 & 1 & 1 \\
\hline C-15 & 1.0491 & 0.9825 & 0.9720 & 0.0667 & 0.0772 & 0.6465 & 0.6126 \\
\hline $\mathrm{C}-20$ & 1.1311 & 0.8985 & 0.8863 & 0.2326 & 0.2449 & 0.3440 & 0.3325 \\
\hline C-25 & 1.0820 & 0.9580 & 0.9056 & 0.1239 & 0.1764 & 0.4961 & 0.4089 \\
\hline $\mathrm{C}-30$ & 1.0656 & 0.9703 & 0.9404 & 0.0953 & 0.1251 & 0.5614 & 0.4936 \\
\hline
\end{tabular}

$$
\gamma_{0 \mathrm{i}}=\frac{1}{n} \sum_{k=1}^{n} \gamma_{0 \mathrm{i}}(k) .
$$

The grey correlations between $\tau_{3}$ and $I_{3}$ and $E$ were 0.6096 and 0.5695 , respectively. According to these calculations, the free-volume aperture size has a larger degree of correlation with the $E$ of the coating, relative to the freevolume concentration.

\section{Conclusion}

This work involved studying the Young's modulus of polyurethane coatings with different diluent contents and testing their microstructure. In addition, grey relation theory was applied to analyze the influence of microstructure indexes on the Young's modulus. The method proposed in this paper can accurately calculate the Young's modulus of the coating, and the test results of its microscan images have the same variation trend as those obtained by the method. The following conclusions can be reached:

(i) Young's modulus of polyurethane coating increases firstly and then decreases with increasing diluent content. (ii) With an increasing diluent content, the aperture size and concentration of the free volume of the coating show a trend of decreasing firstly and then increasing.

(iii) The analysis based on grey relation theory reveals that the aperture size of the free volume has a greater influence on its Young's modulus than the concentration.

The achieved results in this study are important that the requirements of the construction technology and the influence of diluent content on coating properties be considered at the same time to determine the best suited diluent content for the coating when designing polyurethane coatings that can achieve good utility in practical engineering applications.

\section{Data Availability}

The data that support the findings of this study are available from the corresponding author upon reasonable request.

\section{Conflicts of Interest}

The authors declare that there are no conflicts of interest regarding the publication of this study. 


\section{Acknowledgments}

This study was supported by research funds from the National Natural Science Foundation of China (no. 51768033).

\section{References}

[1] A. A. Almusallam, F. M. Khan, S. U. Dulaijan, and O. S. B. AlAmoudi, "Effectiveness of surface coatings in improving concrete durability," Cement and Concrete Composites, vol. 25 , no. 4, pp. 473-481, 2003.

[2] K. H. Kim, M. J. Kim, H. Kim, and K.-Y. Ann, "Effect of hydrophobic surface treatment in lowering ionic transport into concrete," Advances in Materials Science and Engineering, vol. 2020, Article ID 4810259, 13 pages, 2020.

[3] M. Ginic-Markovic, N. R. Choudhury, J. G. Matisons, and D. R. G. Williams, "Characterisation of polyurethane coatings using thermoanalytical techniques," Journal of Thermal Analysis and Calorimetry, vol. 59, no. 1, pp. 409-424, 2000.

[4] X. K. Jiang, J. Y. Gu, and Y. H. Zhang, "The improvement of mechanical properties of polyurethane coating by multiwalled carbon nanotubes," Advanced Materials Research, vol. 236-238, pp. 2063-2066, 2011.

[5] J. Malzbender, G. D. With, and J. M. J. D. Toonder, "Elastic modulus, indentation pressure and fracture toughness of hybrid coatings on glass[J]," Thin Solid Films, vol. 366, no. 1-2, pp. 139-149, 2000.

[6] L. Changjiu, O. Akira, and R. Mcpherson, "The relationship between microstructure and young's modulus of thermally sprayed ceramic coatings," Journal of Materials ence, vol. 32, no. 4, pp. 997-1004, 1997.

[7] T. Shikama, H. Shinno, M. Fukutomi, M. Fujitsuka, and M. Okada, "Mechanical properties of molybdenum coated with titanium carbide film," Journal of Materials Science, vol. 18, no. 10, pp. 3092-3098, 1983.

[8] A. V. Virkar, J. L. Huang, and R. A. Cutler, "Strengthening of oxide ceramics by transformation-induced stress," Journal of the American Ceramic Society, vol. 70, no. 3, pp. 164-170, 1987.

[9] C.-C. Chiu and E. D. Case, "Elastic modulus determination of coating layers as applied to layered ceramic composites," Materials Science and Engineering: A, vol. 132, no. 91, pp. 39-47, 1991.

[10] S. Liu and Q. J. Wang, "Determination of Young's modulus and Poisson's ratio for coatings," Surface and Coatings Technology, vol. 201, no. 14, pp. 6470-6477, 2007.

[11] S. Saalah, L. C. Abdullah, M. M. Aung et al., "Waterborne polyurethane dispersions synthesized from jatropha oil," Industrial Crops and Products, vol. 64, pp. 194-200, 2015.

[12] H.-D. Hwang, C.-H. Park, J.-I. Moon, H.-J. Kim, and T. Masubuchi, "UV-curing behavior and physical properties of waterborne UV-curable polycarbonate-based polyurethane dispersion," Progress in Organic Coatings, vol. 72, no. 4, pp. 663-675, 2011

[13] J. Zheng, R. Ozisik, and R. W. Siegel, "Phase separation and mechanical responses of polyurethane nanocomposites," Polymer, vol. 47, no. 22, pp. 7786-7794, 2006.

[14] C. M. Brunette, S. L. Hsu, and W. J. Macknight, "Hydrogenbonding properties of hard-segment model compounds in polyurethane block copolymers," Macromolecules, vol. 15, no. 1, pp. 71-77, 1982

[15] M. Li, A. Zhao, R. Jiang et al., "Regulation of the elastic modulus of polyurethane microarrays and its influence on gecko-inspired dry adhesion," Applied Surface Science, vol. 257, no. 8, pp. 3336-3340, 2011.

[16] B. Finnigan, D. Martin, P. Halley, R. Truss, and K. Campbell, "Morphology and properties of thermoplastic polyurethane nanocomposites incorporating hydrophilic layered silicates," Polymer, vol. 45, no. 7, pp. 2249-2260, 2004.

[17] B. Han, A. Cheng, G. Ji, S. Wu, and J. Shen, "Effect of organophilic montmorillonite on polyurethane/montmorillonite nanocomposites," Journal of Applied Polymer Science, vol. 91, no. 4, pp. 2536-2542, 2004.

[18] K. Valentine and I. Alojz, "Mechanical characterisation of polyurethane elastomer for biomedical applications," Journal of the Mechanical Behavior of Biomedical Materials, vol. 3, 2010.

[19] L. Núñez-Regueira, M. Villanueva, and I. Fraga-Rivas, "Effect of a reactive diluent on the curing and dynamomechanical properties of an epoxy-diamine system," Journal of Thermal Analysis and Calorimetry, vol. 86, no. 2, pp. 463-468, 2006.

[20] F. Lapique and K. Redford, "Curing effects on viscosity and mechanical properties of a commercial epoxy resin adhesive," International Journal of Adhesion and Adhesives, vol. 22, no. 4, pp. 337-346, 2002.

[21] V. Pascual-Sánchez and J. M. Martin-Martinez, "Influence of the curing temperature in the mechanical and thermal properties of nanosilica filled epoxy resin coating," Macromolecular Symposia, vol. 233, pp. 137-146, 2006.

[22] E. Tomasetti, R. Legras, and B. Nysten, "Quantitative approach towards the measurement of polypropylene/(ethylenepropylene) copolymer blends surface elastic properties by AFM," Nanotechnology, vol. 9, no. 4, pp. 305-315, 1998.

[23] G. G. Bilodeau, "Regular pyramid punch problem," Journal of Applied Mechanics, vol. 59, no. 3, pp. 519-523, 1992.

[24] G. M. Pharr, W. C. Oliver, and F. R. Brotzen, "On the generality of the relationship among contact stiffness, contact area, and elastic modulus during indentation," Journal of Materials Research, vol. 7, no. 3, pp. 613-617, 1992.

[25] A. S. Maxwell, S. Owen-Jones, and N. M. Jennett, "Measurement of Young's modulus and Poisson's ratio of thin coatings using impact excitation and depth-sensing indentation," Review of Scientific Instruments, vol. 75, no. 4, pp. 970-975, 2004.

[26] Y. C. Jean, J. D. Van Horn, W.-S. Hung, and K.-R. Lee, "Perspective of positron annihilation spectroscopy in polymers," Macromolecules, vol. 46, no. 18, pp. 7133-7145, 2013.

[27] T. Sui, L. Wei, X. Cao et al., "Comparison of oxygen vacancy and interstitial oxygen in KDP and ADP crystals from density functional theory calculations," Computational Materials Science, vol. 182, Article ID 109783, 2020.

[28] H. Hertz, "Ueber die Berührung fester elastischer Körper," Journal für die reine und angewandte Mathematik Band, vol. 92, no. 92, pp. 156-171, 1882.

[29] F. Rico, P. Roca-Cusachs, N. Gavara, and R. Farre, "Probing mechanical properties of living cells by atomic force microscopy with blunted pyramidal cantilever tips," Physical Review, vol. 72, Article ID 021914, 2005.

[30] M. Radmacher, M. Fritz, and P. K. Hansma, "Imaging soft samples with the atomic force microscope: gelatin in water and propanol," Biophysical Journal, vol. 69, no. 1, pp. 264-270, 1995.

[31] M. Radmacher, R. W. Tillmann, and H. E. Gaub, "Imaging viscoelasticity by force modulation with the atomic force microscope," Biophysical Journal, vol. 64, no. 3, pp. 735-742, 1993. 
[32] S. G. Shroff, D. R. Saner, and R. Lal, "Dynamic micromechanical properties of cultured rat atrial myocytes measured by atomic force microscopy," American Journal of Physiology - Cell Physiology, vol. 269, no. 1, pp. C286-C292, 1995.

[33] A. B. Mathur, A. M. Collinsworth, W. M. Reichert, W. E. Kraus, and G. A. Truskey, "Endothelial, cardiac muscle and skeletal muscle exhibit different viscous and elastic properties as determined by atomic force microscopy," Journal of Biomechanics, vol. 34, no. 12, pp. 1545-1553, 2001.

[34] B. Cappella and G. Dietler, "Force-distance curves by atomic force microscopy," Surface ence Reports, vol. 34, no. 1-3, 1999.

[35] S. Tan, R. L. Sherman, and W. T. Ford, "Nanoscale compression of polymer microspheres by atomic force microscopy," Langmuir, vol. 20, no. 17, pp. 7015-7020, 2004.

[36] A. L. Lyne, V. Wallqvist, and B. Birgisson, "Adhesive surface characteristics of bitumen binders investigated by Atomic Force Microscopy," Fuel, vol. 113, pp. 248-256, 2013.

[37] L. Lei, Z. Xia, C. Ou, L. Zhang, and L. Zhong, "Effects of crosslinking on adhesion behavior of waterborne polyurethane ink binder," Progress in Organic Coatings, vol. 88, pp. 155-163, 2015.

[38] K.-M. Cheng, C. Tian, Y. Du, F. He, J.-H. Wang, and J. Sun, "Effect of OPS dispersion method on the free volume of polyurethane by positron annihilation lifetime spectroscopy (PALS)," Polymer - Plastics Technology \& Engineering, vol. 51, no. 4, pp. 396-400, 2012.

[39] J. H. Li, R. Y. Hong, M. Y. Li, H. Z. Li, Y. Zheng, and J. Ding, "Effects of $\mathrm{ZnO}$ nanoparticles on the mechanical and antibacterial properties of polyurethane coatings," Progress in Organic Coatings, vol. 64, no. 4, pp. 504-509, 2009.

[40] Z.-P. Zhang, X.-F. Song, L.-Y. Cui, Y.-H. Qi, and L. Y. Cui, "Synthesis of polydimethylsiloxane-modified polyurethane and the structure and properties of its antifouling coatings," Coatings, vol. 8, no. 5, 2018.

[41] D. P. Bakker, F. M. Huijs, J. Vries, J. W. Klijnstra, H. J. Busscher, and H. C. V. D. Mei, "Bacterial deposition to fluoridated and non-fluoridated polyurethane coatings with different elastic modulus and surface tension in a parallel plate and a stagnation point flow chamber," Colloids and Surfaces B: Biointerfaces, vol. 32, no. 3, pp. 179-190, 2003.

[42] G. U. Losi and W. G. Knauss, "Free volume theory and nonlinear thermo visco elasticity," Polymer Engineering \& Science, vol. 32, no. 8, pp. 542-557, 2010.

[43] J. Borek and W. Osoba, "Free volume changes in physically aged polyethylene by positron annihilation,” Polymer, vol. 42, no. 7, pp. 2901-2905, 2001.

[44] S. Goyanes, G. Rubiolo, A. Marzocca et al., "Yield and internal stresses in aluminum filled epoxy resin. A compression test and positron annihilation analysis," Polymer, vol. 44, no. 11, pp. 3193-3199, 2003.

[45] Q. Deng and Y. C. Jean, "Free-volume distributions of an epoxy polymer probed by positron annihilation: pressure dependence," Macromolecules, vol. 26, no. 1, pp. 30-34, 1993.

[46] E. Gomaa and J. N. Asaad, "Effect of adding feldspar on free volume properties of crosslinked polyester studied by positron annihilation lifetime spectroscopy," Journal of Applied Polymer Science, vol. 124, no. 4, pp. 3142-3146, 2012.

[47] M. A. H. El-Meniawi, K. R. Mahmoud, and M. Megahed, "Positron annihilation spectroscopy and mechanical properties studies for epoxy matrices reinforced with different nanoparticles," Journal of Polymer Research, vol. 23, no. 9, p. 181, 2016.
[48] Y. C. Jean, "Positron annihilation spectroscopy for chemical analysis: a novel probe for microstructural analysis of polymers," Microchemical Journal, vol. 42, no. 1, pp. 72-102, 1990.

[49] B. Wang, W. Gong, W. H. Liu et al., "Influence of physical aging and side group on the free volume of epoxy resins probed by positron," Polymer, vol. 44, no. 14, pp. 4047-4052, 2003.

[50] M. Forsyth, P. Meakin, D. R. Macfarlane, and A. J. Hill, "Free volume and conductivity of plasticized polyether-urethane solid polymer electrolytes," Journal of Physics: Condensed Matter, vol. 7, no. 39, pp. 7601-7617, 1999.

[51] H. Nakanishi, Y. C. Jean, E. G. Smith, and T. C. Sandreczki, "Positronium formation at free-volume sites in the amorphous regions of semicrystalline PEEK," Journal of Polymer Science Part B: Polymer Physics, vol. 27, no. 7, pp. 1419-1424, 1989.

[52] L. Boogh, B. Pettersson, and J.-A. E. Månson, "Dendritic hyperbranched polymers as tougheners for epoxy resins," Polymer, vol. 40, no. 9, pp. 2249-2261, 1999.

[53] X. Q. Liu and N. Zhang, "Research on multi-criteria decision based on bidirectional grey relation projection method," Advanced Materials Research, vol. 940, pp. 441-444, 2014. 